\title{
Comparison of cervical disc arthroplasty and anterior cervical discectomy and fusion for the treatment of cervical disc degenerative diseases on the basis of more than 60 months of follow-up: a systematic review and meta-analysis
}

Yijian Zhang ${ }^{1,2+}$, Nanning $\mathrm{Lv}^{3+}$, Fan $\mathrm{He}^{1,2}$, Bin $\mathrm{Pi}^{1,2}, \mathrm{Hao} \mathrm{Liu}^{1,2}$, Angela Carley Chen ${ }^{4}$, Huilin Yang ${ }^{1,2}$, Mingming Liu ${ }^{3^{*}}$ and Xuesong Zhu $\mathrm{u}^{1,2^{*}}$

\begin{abstract}
Background: This meta-analysis was designed to investigate the long-term efficacy and safety between cervical disc arthroplasty (CDA) and anterior cervical discectomy and fusion (ACDF) in treating cervical disc degenerative diseases (CDDDs).
\end{abstract}

Methods: Literature search was performed on Pubmed, Embase, Cochrane Library, and Web of Science before Jan 2019. Surgical details, clinical outcomes, range of motion (ROM), complications, and reoperation rates between CDA and ACDF groups were compared and analyzed. A fixed- or random-effects model was applied based on different heterogeneity. STATA (Version 11.0) software was used to perform data analysis.

Results: A total of 13 randomized controlled trial studies with more than 60 months of follow-up (mean 83.1 months) were enrolled in this meta-analysis. Pool results indicated that the CDA group exhibited significantly better outcomes in clinical scores (odds ratio [OR] $=1.54,95 \%$ confidence interval [CI]: 1.15-2.08, $p=0.004$ ) and preservation of ROM (mean difference $=1.77,95 \% \mathrm{Cl}: 1.60-1.95, p<0.001$ ) than the ACDF group. Meanwhile, the incidence of adjacent segment disease (ASD) (OR $=0.51,95 \% \mathrm{Cl}: 0.35-0.76, p=0.001)$ and occurrence of reoperation $(\mathrm{OR}=0.41,95 \% \mathrm{Cl}: 0.25-0.69, p=0.001)$ were lower in the CDA group than in the ACDF group.

(Continued on next page)

\footnotetext{
*Correspondence: drliumingming@163.com; sudazxs@sina.com

${ }^{\dagger}$ Yijian Zhang and Nanning Lv contributed equally to this work.

${ }^{3}$ Department of Orthopedic Surgery, The Second People's Hospital of Lianyungang, Lianyungang 222003, Jiangsu, China

1 Department of Orthopedics, The First Affiliated Hospital of Soochow University, 899, Pinghai Road, Suzhou 215006, China

Full list of author information is available at the end of the article
}

(c) The Author(s). 2020 Open Access This article is licensed under a Creative Commons Attribution 4.0 International License, which permits use, sharing, adaptation, distribution and reproduction in any medium or format, as long as you give appropriate credit to the original author(s) and the source, provide a link to the Creative Commons licence, and indicate if changes were made. The images or other third party material in this article are included in the article's Creative Commons licence, unless indicated otherwise in a credit line to the material. If material is not included in the article's Creative Commons licence and your intended use is not permitted by statutory regulation or exceeds the permitted use, you will need to obtain permission directly from the copyright holder. To view a copy of this licence, visit http://creativecommons.org/licenses/by/4.0/. The Creative Commons Public Domain Dedication waiver (http://creativecommons.org/publicdomain/zero/1.0/) applies to the data made available in this article, unless otherwise stated in a credit line to the data. 
(Continued from previous page)

Conclusions: At long-term follow-up, CDA showed better efficacy in terms of clinical outcomes, ROM, ASD, and reoperation than ACDF for treating CDDDs. However, our results require further validation in large-sample and high-quality studies.

Keywords: Cervical disc arthroplasty, Anterior cervical discectomy and fusion, Cervical degenerative disc diseases, Long-term follow-up

\section{Background}

In the past several decades, anterior cervical discectomy and fusion (ACDF) has been applied to multiple cervical disorders, including cervical spondylotic myelopathy, cervical spondylotic radiculopathy, and cervical ossification of posterior longitudinal ligament, for its satisfactory clinical efficacy [1]. In the ACDF procedure, directed decompression of the nucleus pulposus and osteophyte can be performed under clear vision during operation [2]. Meanwhile, the physical sagittal alignment of cervical spine can be restored with the inserted cage in the intervertebral space, fixed screws, and anterior plates [3]. However, a solid bony fusion in this procedure can change the range of motion (ROM) and mechanical load of adjacent segments, which can cause subsequent adjacent segment disease (ASD) [4].

Therefore, to decrease the risk of ASD in cervical surgery, cervical disc arthroplasty (CDA) was introduced as an alternative treatment for cervical disc degenerative diseases (CDDDs) in the past 20 years [5]. With a mobile device between two contiguous vertebrae, the mobility of operated segments can be preserved, which may potentially decrease the incidence of ASD postoperatively [6]. Moreover, CDA was reported to show better improvement in clinical functions than fusion surgery because the normal kinematics of the involved segments are maintained [7]. Numerous studies have compared the clinical results and complications between CDA and ACDF, but the conclusions are inconsistent $[8,9]$.

Though several meta-analyses have compared CDA and ACDF, most of them are based on short-term follow-ups [10, 11]. To the best of our knowledge, few studies have examined the long-term efficacy between the two procedures. Hence, in the present study, we performed a systematic review and meta-analysis to investigate the long-term radiographic data, clinical outcomes, and other complications between CDA and ACDF for the treatment of CDDDs.

\section{Methods}

\section{Literature search}

The present meta-analysis was based on the guidelines listed in the Preferred Reporting Items for Systematic Reviews and Meta-Analysis statement [12]. Electronic search was performed on PubMed, Embase, Scopus,
Cochrane Database, and Web of Science from the dates of inception to January 2019. In the search strategy, the following controlled vocabulary (Emtree of Embase and $\mathrm{MeSH}$ of PubMed) and keywords were used: ("cervical disc arthroplasty" OR "cervical disc replacement" OR "CDA" OR "CDR") AND ("anterior cervical discectomy and fusion" OR "ACDF"). The reference lists of the enrolled studies were searched for missed eligible studies. The literature search was restricted to the English language.

\section{Selection criteria}

The inclusion criteria for identification of studies were as follows: (1) randomized controlled trials (RCTs), (2) comparison between two surgical procedures (CDA and ACDF), (3) follow-up time of more than 60 months, and (4) reporting at least one surgical related outcome. The studies that satisfied the following criteria were eliminated: (1) lack of comparative data, (2) insufficient follow-up, and (3) biomechanical or in vitro studies.

\section{Assessment of quality}

To evaluate the quality of evidence of the identified studies, the Cochrane Collaboration tool was used to assess the RCTs [13]. Each identified trial was reviewed and scored as high, low, and unclear risks according to selection, performance, detection, attribution, reporting, and other potential biases. Two reviewers ( $\mathrm{YJ} \mathrm{Z}$ and $\mathrm{B} \mathrm{P})$ reviewed and assessed each study independently, and a third reviewer (HL Y) was consulted to solve disagreements.

\section{Data extraction}

The data extracted from the enrolled studies for synthesis and analysis included authors, date of publication, study design, study country, patient characteristics (distribution of sex and age), surgical prosthesis, follow-up, neurological success, overall success, neck disability index (NDI), short-form questionnaire for physical health (SF-PCS), arm pain, neck pain, ROM, ASD, adverse events, reoperation at index level, and reoperation at adjacent level.

\section{Statistical analysis}

Meta-analysis was performed using the STATA (Version 11.0) software. For binary variables, the odds ratio (OR) 

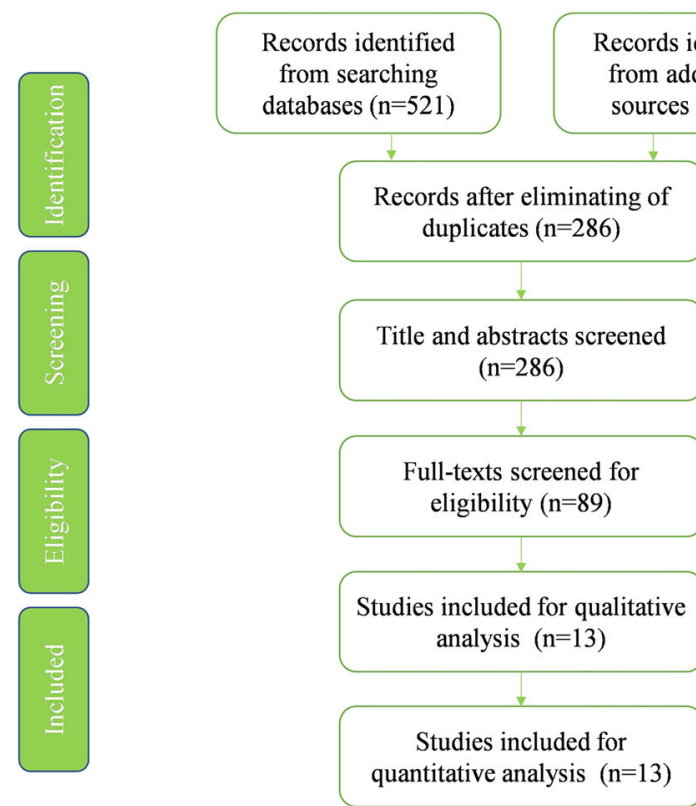

Fig. 1 Study flow diagram of literature search

was used for evaluation, while mean difference (MD) was applied for continuous variables. The heterogeneity of studies was estimated using the $I^{2}$ tests: low heterogeneity $\left(I^{2}<30 \%\right)$, moderate heterogeneity $\left(30 \%<I^{2}<\right.$ $50 \%)$, and substantial heterogeneity $\left(I^{2}>50 \%\right)$. The fixed-effects model was adopted when $I^{2}<50 \%$, and the random-effects model was applied when $I^{2}>50 \%$. The minimal clinically important difference (MCID) for NDI, SF-PCS, arm pain and neck pain was set as 2.5 according to previous studies [14, 15]. Publication bias was assessed by Egger's test, and sensitivity analysis was used to confirm the stability of results. A two-tail $p$-value of less than 0.05 was considered significant.

\section{Results}

\section{Search results}

A total of 569 studies were searched at the initial searching process. After eliminating of duplicate studies, 286 studies were screened based on titles and abstracts. The 89 potential eligible studies that remained were full-text reviewed. Ultimately, 13 articles were enrolled in this

Table 1 Characteristics of 13 enrolled RCT studies

\begin{tabular}{|c|c|c|c|c|c|c|c|c|c|}
\hline Authors & Year & $\mathrm{CDA}(\mathrm{N})$ & CDA (Age) & CDA (Male \%) & $\mathrm{ACDF}(\mathrm{N})$ & ACDF (Age) & ACDF (Male \%) & Prothesis & Follow-up \\
\hline Burkus et al. & 2014 & 276 & 43.3 & 46.4 & 265 & 43.9 & 46.0 & Prestige & 84 months \\
\hline Coric et al. & 2013 & 41 & 49.5 & 39.0 & 33 & 49.3 & 42.4 & Bryan and KineflexC & 72 months \\
\hline Ghobrial et al. & 2018 & 242 & Not provided & Not provided & 221 & Not provided & Not provided & Bryan & 120 months \\
\hline Gornet et al. & 2016 & 280 & $44.5 \pm 8.8$ & 46.1 & 265 & $43.9 \pm 8.8$ & 46 & Prestige LP & 84 months \\
\hline Hisey et al. & 2016 & 164 & $43.3 \pm 9.2$ & 47.6 & 81 & $44.0 \pm 8.2$ & 44.4 & Mobi-C & 60 months \\
\hline Jackson et al. & 2016 & 413 & Not provided & Not provided & 186 & Not provided & Not provided & Mobi-C & 60 months \\
\hline Janssen et al. & 2015 & 103 & $42.1 \pm 8.4$ & 45 & 106 & $43.5 \pm 7.2$ & 46 & ProDisc-C & 84 months \\
\hline Lanman et al. & 2017 & 209 & $47.1 \pm 8.3$ & 44 & 188 & $47.3 \pm 7.7$ & 47.9 & Prestige LP & 84 months \\
\hline Loimeau et al. & 2016 & 22 & Not provided & Not provided & 22 & Not provided & Not provided & ProDisc-C & 84 months \\
\hline Miller et al. & 2018 & 34 & Not provided & Not provided & 36 & Not provided & Not provided & Bryan & 84 months \\
\hline Philips et al. & 2015 & 224 & Not provided & Not provided & 192 & Not provided & Not provided & PCM & 60 months \\
\hline Radcliff et al. & 2017 & 389 & $44.5 \pm 8.6$ & 49 & 186 & $45.2 \pm 8.1$ & 43.5 & Mobi-C & 84 months \\
\hline Sasso et al. & 2016 & 22 & Not provided & Not provided & 25 & Not provided & Not provided & Bryan & 120 months \\
\hline
\end{tabular}


meta-analysis for qualitative and quantitative analyses (Fig. 1).

\section{Demographic data}

Thirteen RCT studies published between 2013 and 2018 were included in the present study. The distributions of prosthesis in CDA were Bryan (3 studies), Bryan and KineflexC (1 study), Prestige (1 study), Prestige LP (2 study), ProDisc-C (2 studies), Mobi-C (3 studies), and PCM (1 study). The mean follow-up of the enrolled studies was 83.1 months, ranging from 60 months to 120 months. The specific characteristics of all included studies are listed in Table 1.

\section{Quality assessment}

The majority of the 13 eligible studies were well designed and of high quality. All studies were rated as "low risk of bias" according to the Cochrane Handbook for Systematic Review of Interventions (Fig. 2).

\section{Meta-analysis outcome}

Neurological success was reported in six studies [16-21] that comprised 944 patients in the CDA group and 747 patients in the ACDF group. The pooled results indicated that the neurological success rate in the CDA group was significantly higher than that in the ACDF group $(\mathrm{OR}=1.54$, 95\% confidence interval $[\mathrm{CI}]$ : $1.14-$ $2.08, p=0.004)$ with moderate heterogeneity $\left(I^{2}=34.0 \%\right.$, $p=0.18$ ) (Fig. 3). Overall success was reported in four studies [16, 20-22] that comprised 620 patients in the $\mathrm{CDA}$ group and 418 patients in the ACDF group. The pooled results indicated that the overall success rate in the CDA group was also significantly higher than that in the ACDF group (OR $=1.68,95 \%$ CI: $1.29-2.19, p<$ $0.001)$ with low heterogeneity $\left(I^{2}=0 \%, p=0.62\right)$ (Fig. 4).

NDI was provided in three studies $[16,20,23]$ that comprised 398 patients in the CDA group and 305 patients in the ACDF group. The pooled results indicated that the NDI in the CDA group was significantly lower than that in the ACDF group ( $\mathrm{MD}=-0.20,95 \% \mathrm{CI}$ : 0.36 to $-0.05, p=0.009$ ), with moderate heterogeneity $\left(I^{2}=37.8 \%, p=0.20\right)$ while the effective size of NDI did not exceed the MCID. SF-PCS was obtained from two studies $[16,20]$ that comprised 376 patients in the CDA group and 264 patients in the ACDF group. The pooled results indicated that the SF-PCS scores were higher in the CDA group than in the ACDF group, with a clear tendency to significance ( $\mathrm{MD}=0.16,95 \% \mathrm{CI}$ : -0.00 $0.32, p=0.05)$ and an inconspicuous heterogeneity $\left(I^{2}=\right.$ $0 \%, p=0.995)$ while the effective size of SF-PCS did not exceed the MCID (Fig. 5).

Arm and neck pains were provided in three studies $[16,20,23]$ that comprised 398 patients in the CDA group and 305 patients in the ACDF group. The pooled results indicated that both neck and arm pains were significantly better in the CDA group than in the ACDF group $(\mathrm{MD}=-0.20,95 \% \mathrm{CI}:-0.35$ to $-0.05, p=0.01$ and $\mathrm{MD}=-0.23,95 \% \mathrm{CI}:-0.38$ to $-0.07, p=0.004$, respectively), with inconspicuous heterogeneity $\left(I^{2}=31.6 \%\right.$, $p=0.23$ and $I^{2}=24.3 \%, p=0.27$, respectively). The

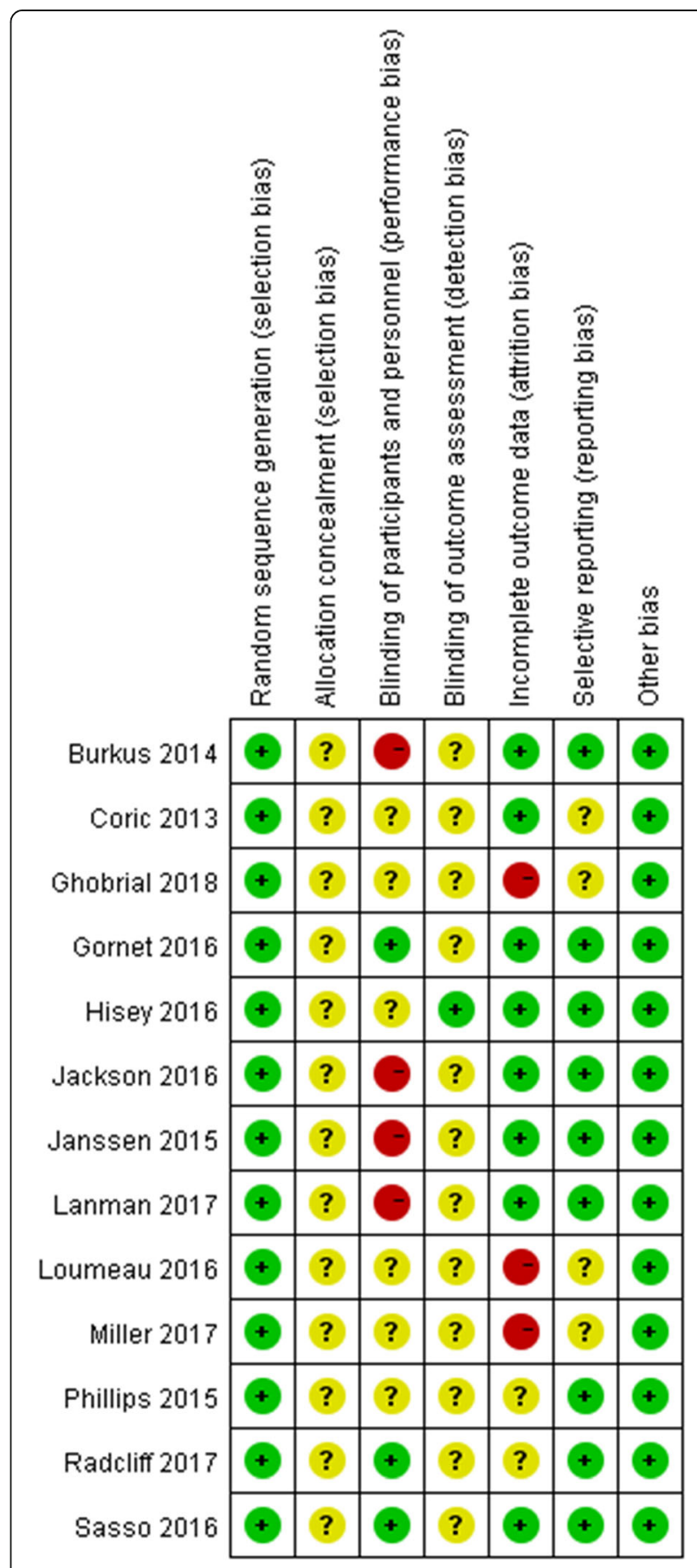

Fig. 2 Assessment of risk of bias for RCT: "+": low risk of bias; "-": high risk of bias; "?": unclear risk of bias 


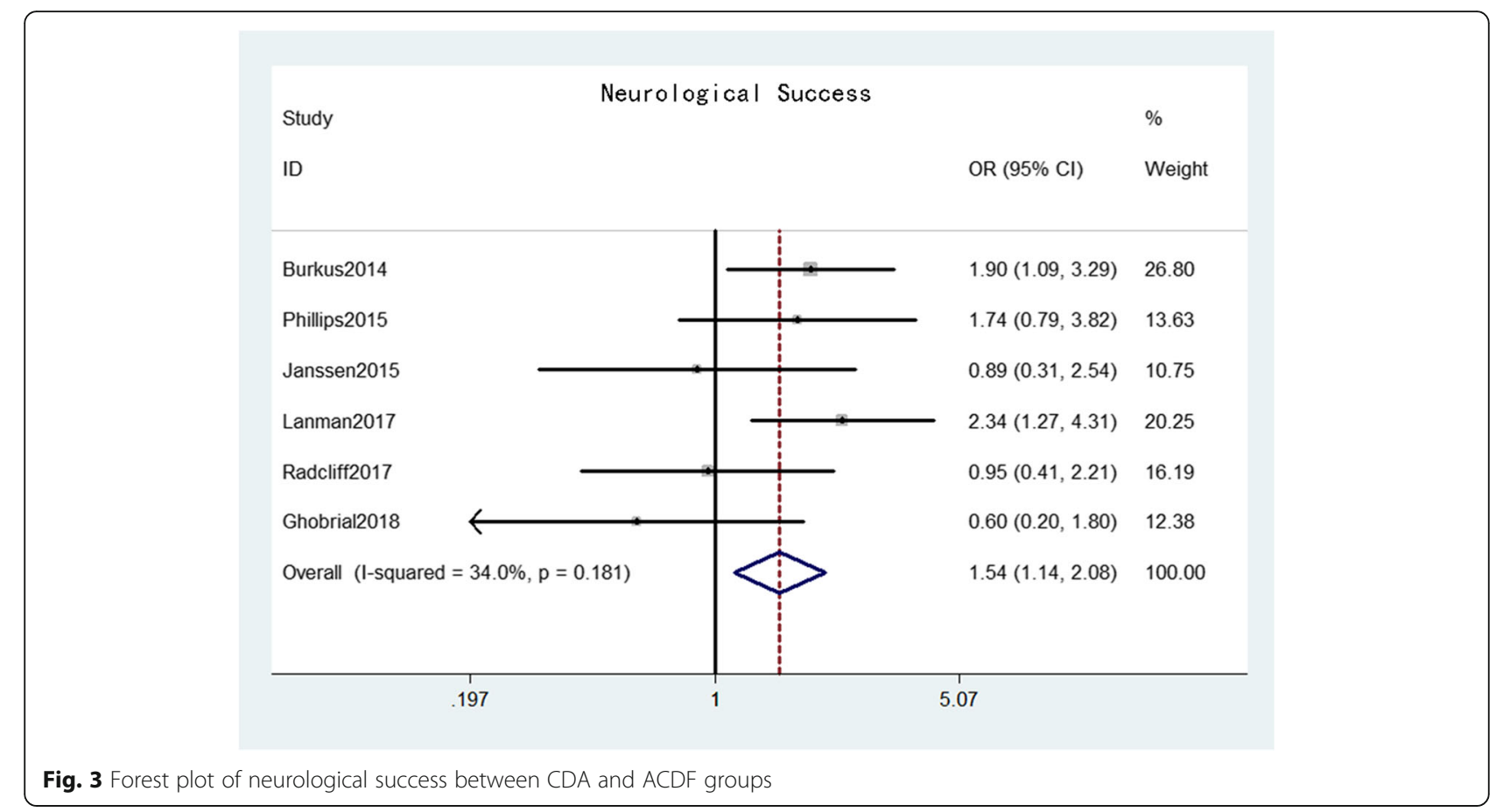

effective size of arm and neck pains did not exceed the MCID (Fig. 6).

ROM was reported in three studies $[17,18,20]$ that comprised 400 patients in the CDA group and 274 patients in the ACDF group. The pooled results indicated that the ROM in the CDA group was significantly larger than that in the ACDF group (MD $=1.76,95 \% \mathrm{CI}: 1.57-$ 1.94, $p<0.001)$ with low heterogeneity $\left(I^{2}=0 \%, p=\right.$ $0.38)$. ASD was provided from three studies $[20,22,24]$ that comprised 302 patients in the CDA group and 160 patients in the ACDF group. The pooled results indicated that the ASD rate in the CDA group was

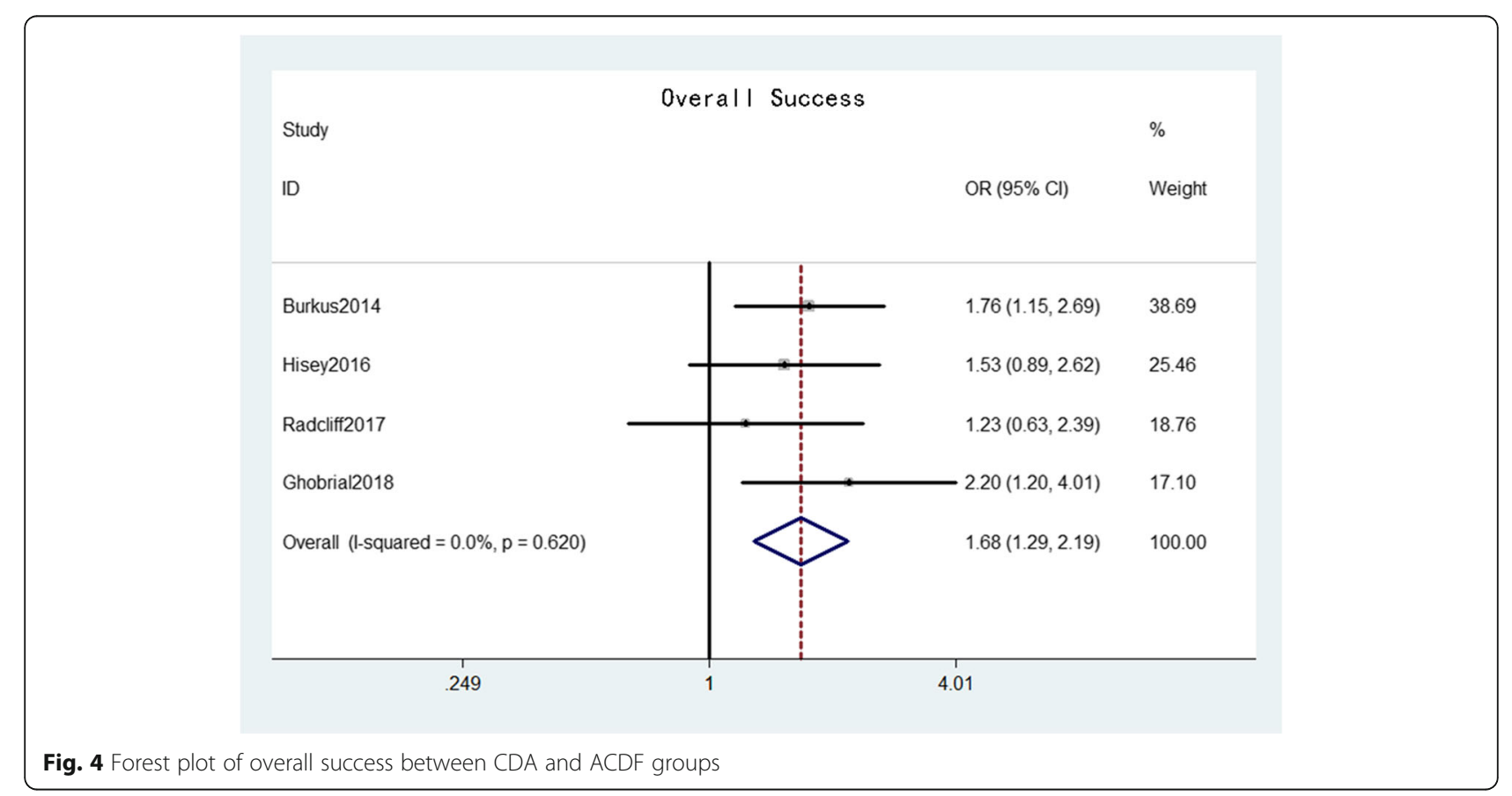




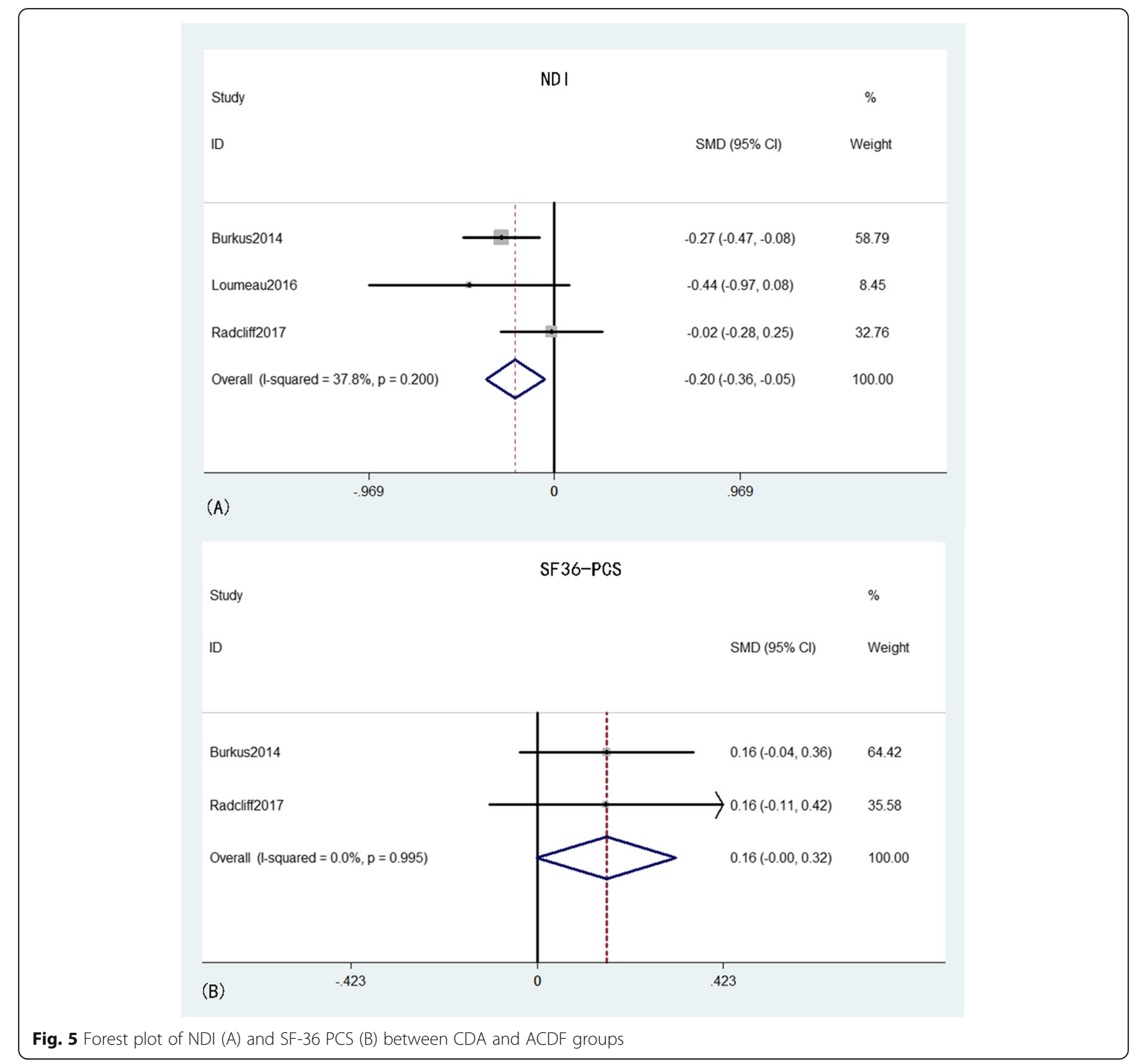

significantly lower than that in the ACDF group (OR = $0.51,95 \%$ CI: $0.35-0.76, p=0.001)$, with moderate heterogeneity $\left(I^{2}=32.9 \%, p=0.23\right)$ (Fig. 7).

The adverse event rate was provided from seven studies $[17-20,22,25,26]$ that comprised 1145 patients in the CDA group and 901 patients in the ACDF group. The pooled results indicated the adverse event rate was not significant between the two groups (OR $=1.01,95 \%$ CI: $0.77-1.32, p=0.96)$, with low heterogeneity $\left(I^{2}=\right.$ $8.4 \%, p=0.37$ ) (Fig. 8).

Reoperation at the index level was provided from 11 studies [16-20, 22, 23, 25-28] that comprised 1811 patients in the CDA group and 1330 patients in the ACDF group. The pooled results indicated that reoperation at the index level rate was significantly lower in the CDA group than in the ACDF group $(\mathrm{OR}=0.41,95 \% \mathrm{CI}$ : $0.25-0.69, p=0.001$ ), with substantial heterogeneity $\left(I^{2}=61.0 \%, p=0.004\right)$ (Fig. 9).

Reoperation at the adjacent level was provided from 11 studies [16-23, 25, 27, 28] that comprised 1773 patients in the CDA group and 1286 patients in the ACDF group. The pooled results indicated that reoperation at the adjacent level rate was significantly lower in the CDA group than in the ACDF group (OR $=0.34,95 \%$ CI: $0.26-0.46, p<0.001)$, with low heterogeneity $\left(I^{2}=\right.$ 23.4\%, $p=0.22$ ) (Fig. 10). 


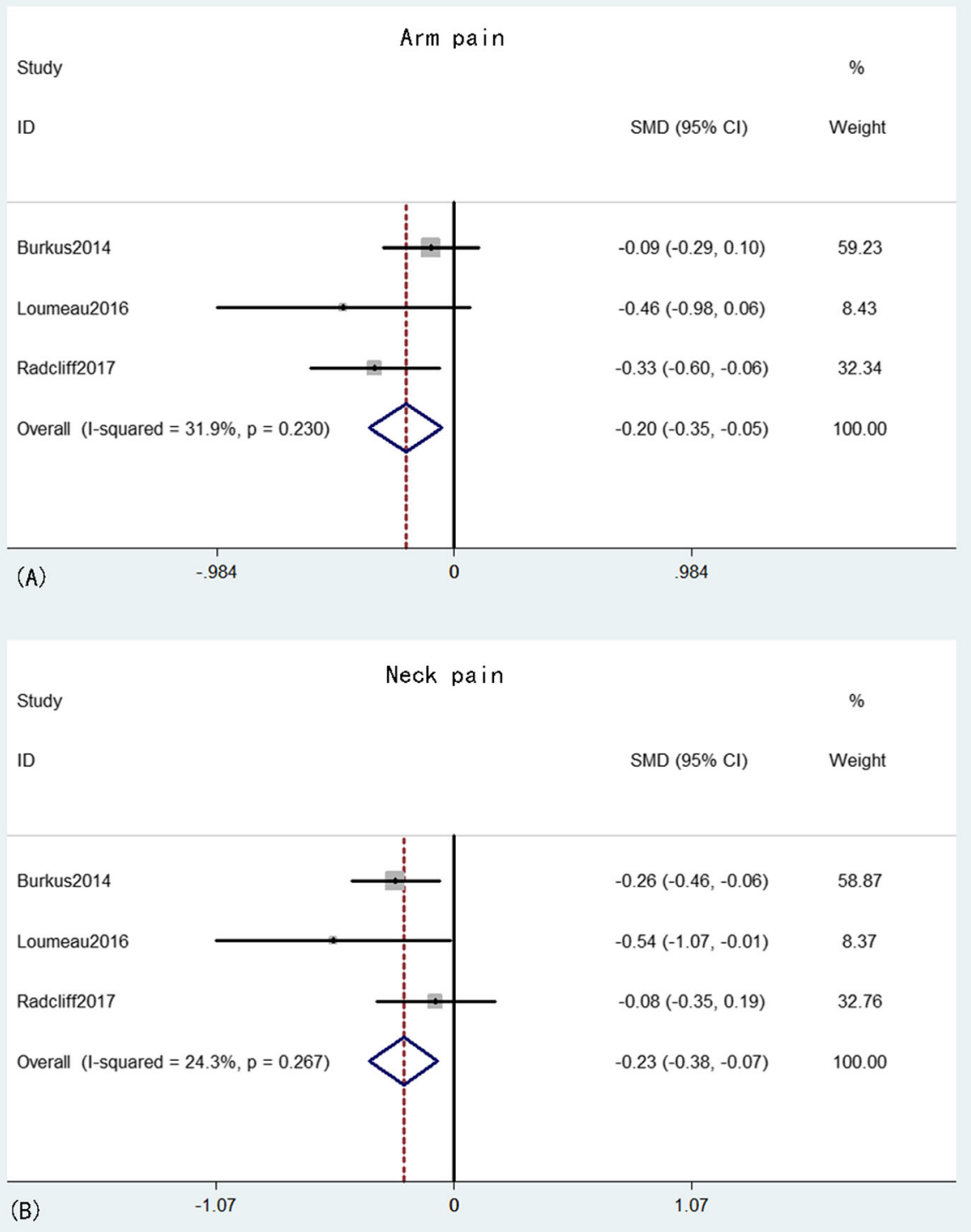

Fig. 6 Forest plot of arm pain (A) and neck pain (B) between CDA and ACDF groups

\section{Publication bias}

Publication bias was investigated using Begg's test, and Begg's funnel plot was constructed to evaluate the publication bias of the included studies. No studies showed obvious asymmetry on two sides, indicating a low publication bias in the present study (Supplement 1).

\section{Sensitivity analysis}

Sensitivity analysis was performed to examine whether removing each study would make a significant change on the overall trend. No altered results were observed after each study was eliminated, suggesting the reliability and stability of results in this meta-analysis (Supplement 2).

\section{Discussion}

ACDF has been applied as an optimal surgical procedure for treating cervical degenerative diseases since it was first reported in 1958 by Robinson and Smith [29]. However, with the widespread use of this procedure, some complications, including decrease of ROM, emergence of ASD, and reoperation, have drawn significant attention. Previous studies reported that the loss of mobility of surgical segments caused by fusion may be a potential reason for ASD and reoperation. By contrast, as a nonfusion decompression method, CDA can preserve the motion of index segments and the natural cervical alignment. ROM, at either operative or adjacent levels, can be maintained effectively after CDA [30]. In recent years, 


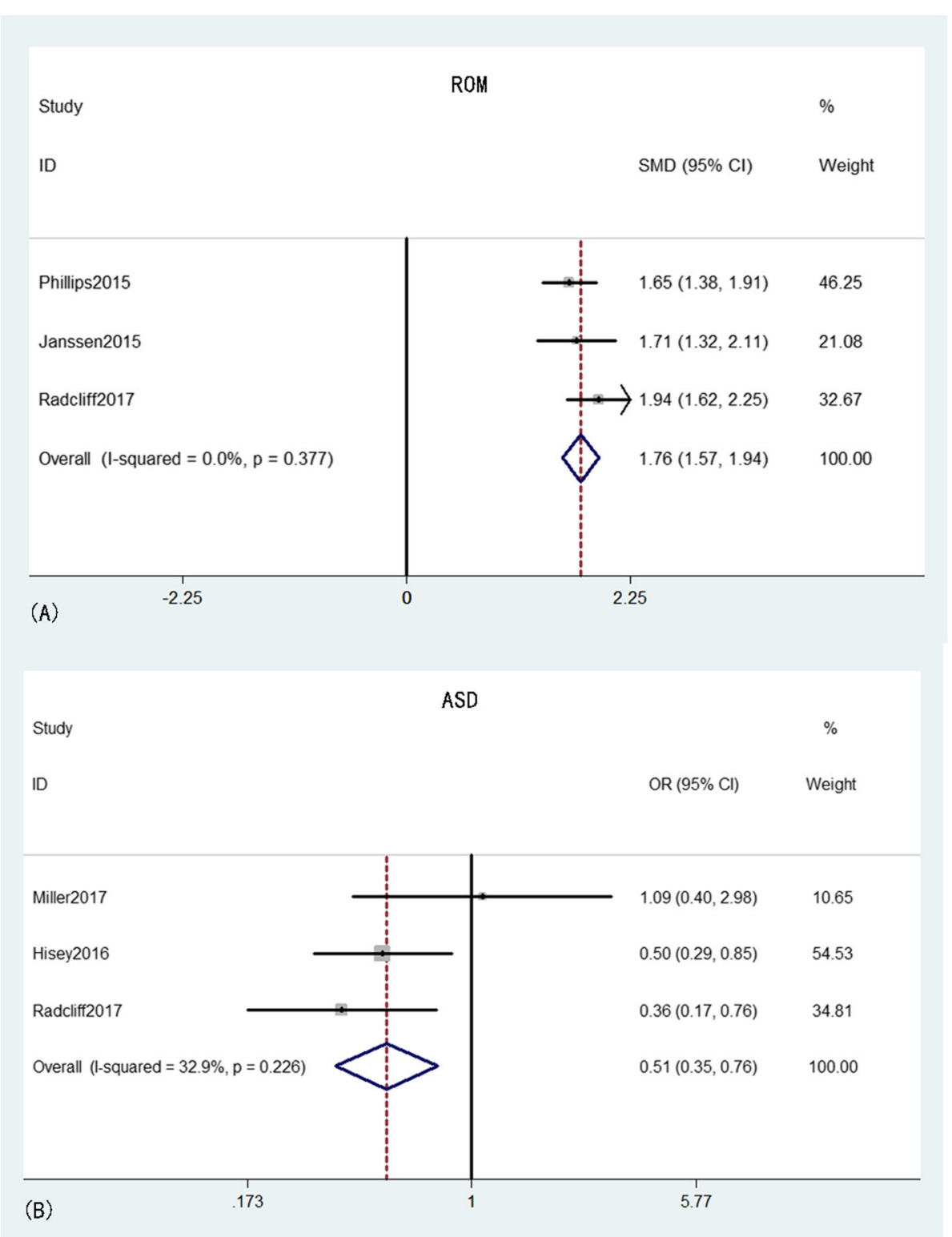

Fig. 7 Forest plot of ROM (A) and ASD (B) between CDA and ACDF groups

numerous meta-analyses compared the clinical and radiological outcomes between $\mathrm{ACDF}$ and $\mathrm{CDA}$ to evaluate whether the latter is better at reducing related complications. Luo et al. reported that CDA has significantly lower incidence of ASD and adjacent segment reoperations in cervical degenerative diseases than ACDF [31]. Similar results were also verified in another study, indicating the superior effect of CDA through the fewer adjacent segmental complications [32]. Meanwhile, some studies demonstrated that CDA may show better clinical outcomes and fewer postoperative adverse events than ACDF [33]. Unfortunately, most of them reported short- or mid-term outcomes between the two procedures, while long-term results were still unclear.
In this meta-analysis, the authors conducted a comparison between the surgical successes, clinical outcomes, ROMs, ASDs, and reoperations between CDA and ACDF on the basis of more than 60 months followup and obtained meaningful results. For clinical outcomes, at a mean of 83.1 months of follow-up, the NDI, SF-PCS, and neck and arm pains in the CDA group were better than those in the ACDF group, indicating that dynamic implant can achieve better clinical outcomes. However, for the clinical relevance, none of these parameters met the MCID. Therefore, we considered the superior curative outcomes for pain management need more studies to verify. The rates of neurological and overall successes were also higher in the CDA group 


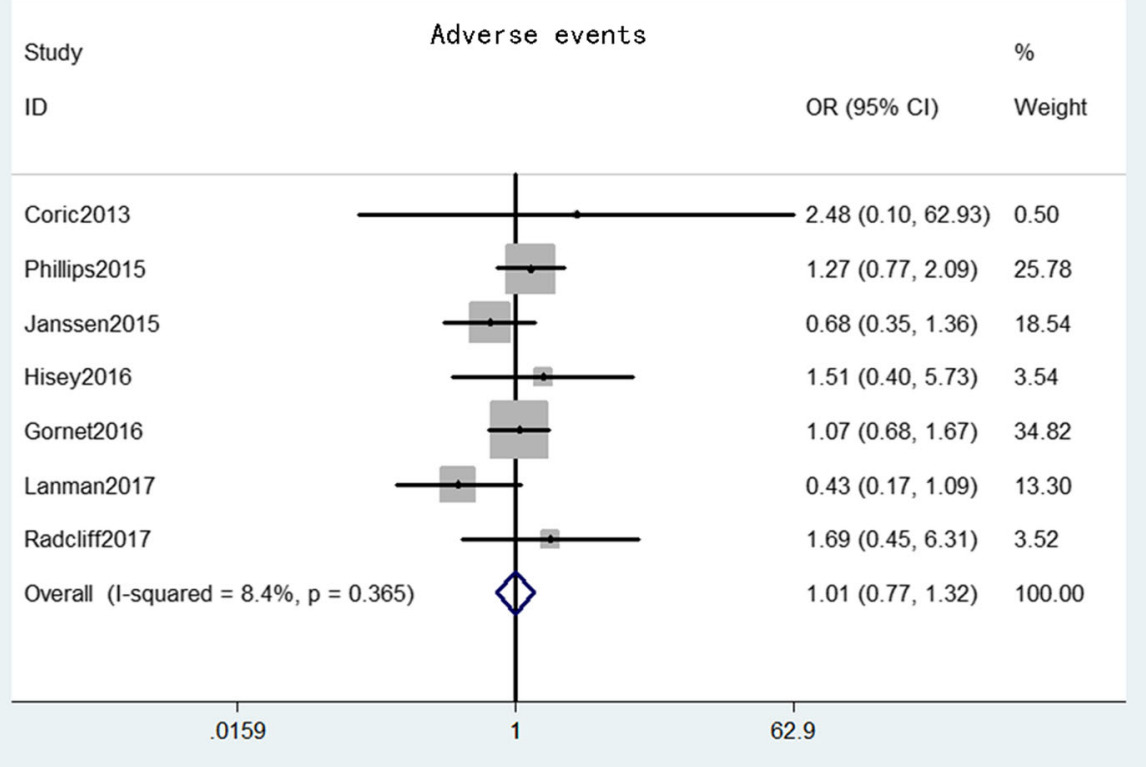

Fig. 8 Forest plot of adverse events between CDA and ACDF groups

than in the ACDF group. Both CDA and ACDF can relieve pain symptoms by the adequate decompression of the herniated disc or osteophyte under direct vision through the anterior approach. Meanwhile, compared with $\mathrm{ACDF}, \mathrm{CDA}$ can preserve the cervical mobility and provide a normal motion pattern of the intact spine, which may be a potential cause of the superior clinical outcomes in the CDA group [34].

As a dynamic device, CDA was designed to preserve the activity of surgical segments, which prevents long-

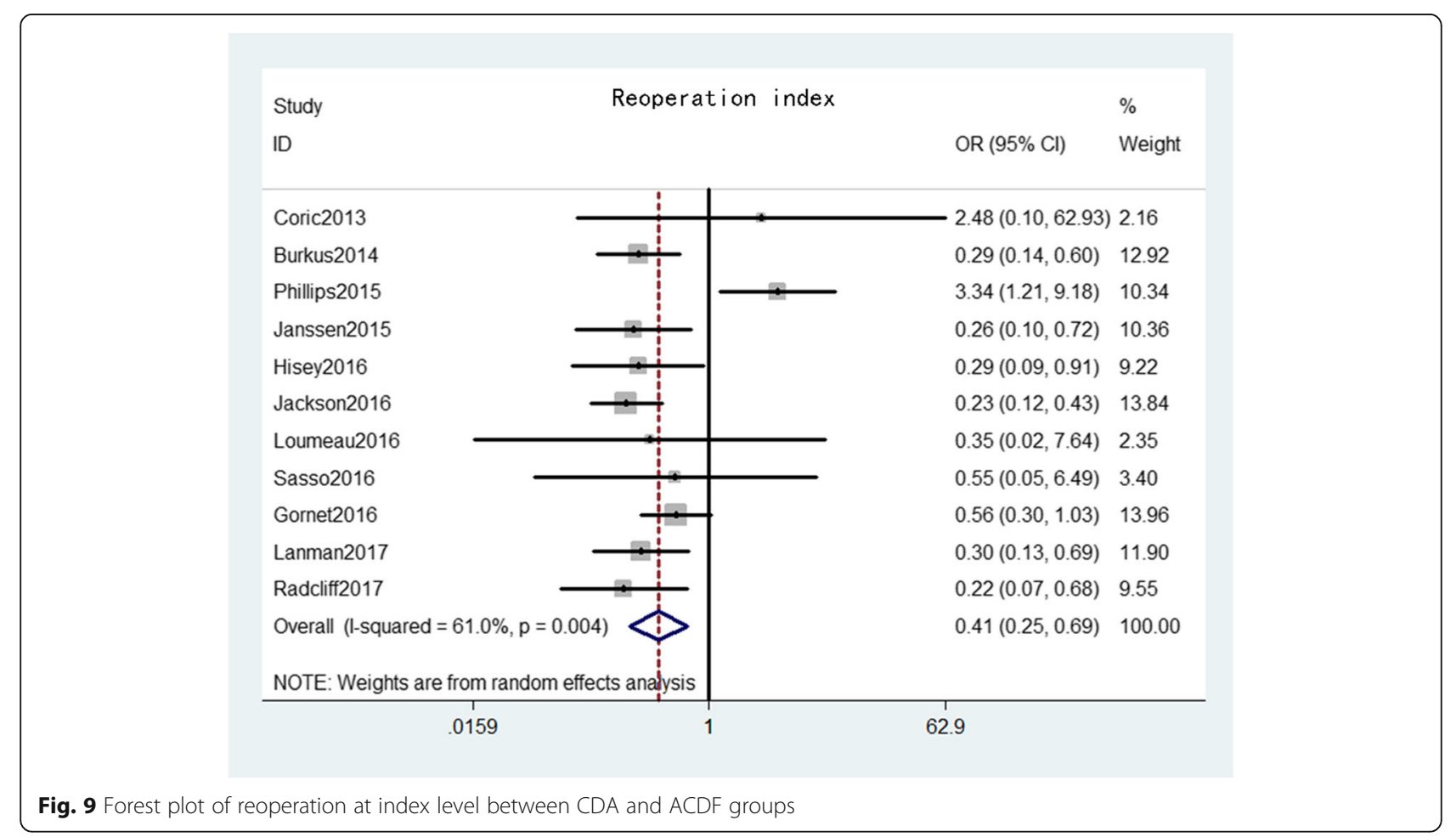




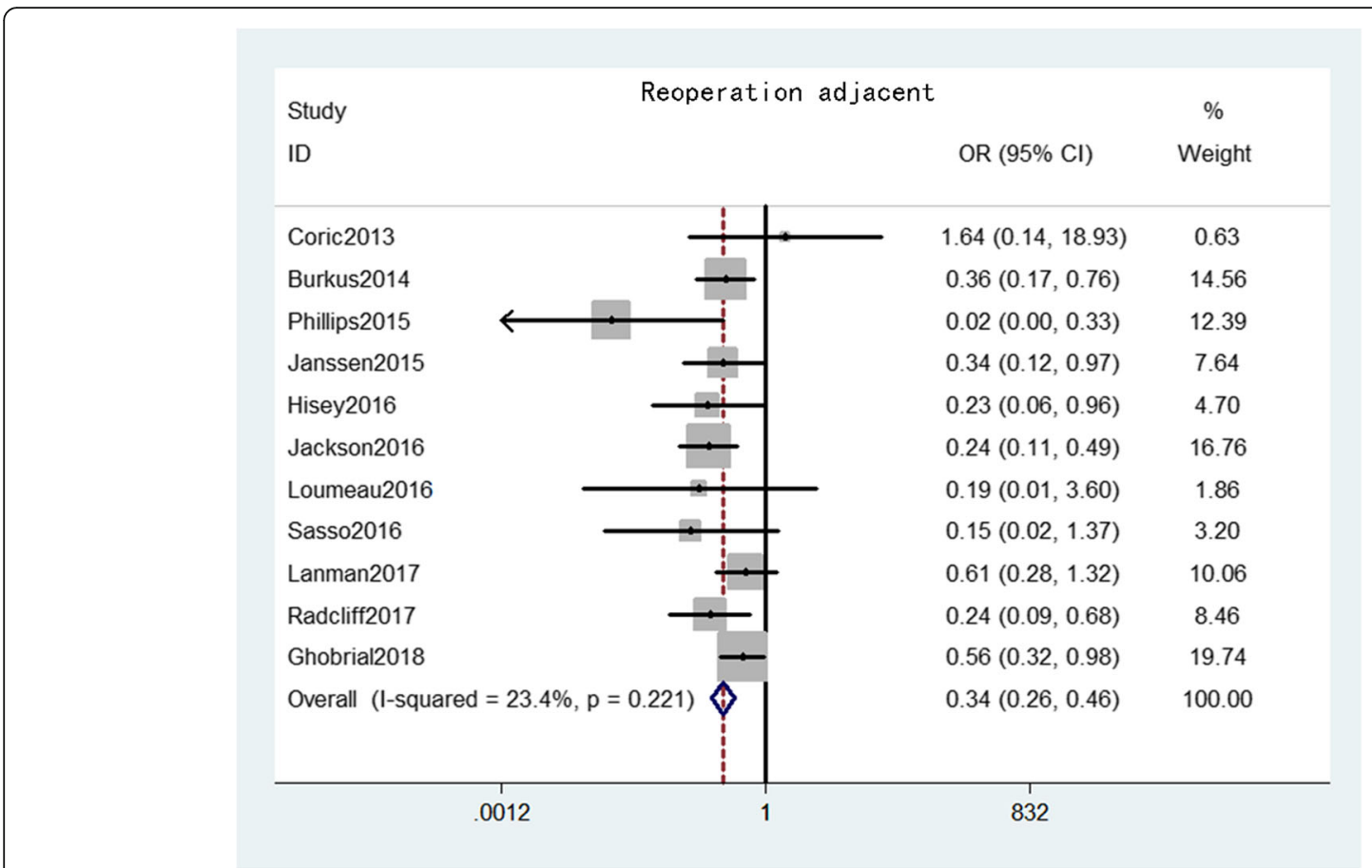

Fig. 10 Forest plot of reoperation at adjacent level between CDA and ACDF groups

term complications, such as ASD, neck stiffness, and revision. Zeng et al. conducted a seven-year follow-up and observed that the segment motion in the Prestige-LP Disc can be preserved effectively at the final follow-up [35]. Tian et al. performed a comparative study between Bryan disc and anterior fusion surgery, and their results corroborated that the ROM of the former is explicitly better and the mobility can be maintained after 6 years of follow-up [36]. In the present study, as theoretically predicted, the ROM in the CDA group was significantly higher than that in the ACDF group at long-term follow-up, which is consistent with previous studies [17, 18]. Additionally, we observed from the included studies that the ROM can be maintained well and even improved slightly in CDA patients, indicating the satisfactory effect of CDA on the preservation of segmental motion. For patients who demand normal working and mild activity, such maintenance of cervical mobility may benefit the quality of life.

As for complications, though no significant difference in the adverse events was observed between CDA and ACDF. It was worth noting that as a common complication after cervical surgery, the incidence of ASD was seem lower in the CDA group than in the ACDF group with our statistical results, which reveals that CDA may have a potential positive impact on reducing postoperative ASD at long-term follow-up. As mentioned above, due to the loss of segmental motion, patients after ACDF may have abnormal mobility at adjacent levels that can alter the biomechanical load and exacerbate degeneration of adjacent vertebrae [37]. Compared with fusion surgery, the mobility and flexibility of operative levels can be preserved in the CDA group, and a physiological functional spinal unit (FSU) can be conserved, which may benefit the natural degenerative process. Finally, the reoperation rates of the two groups were compared, and CDA exhibited a favorable effect due to the lower reoperation rate, whether at index or adjacent segments [21, 24]. Without doubt, a second operation is another trauma for patients, and prior tissue and scar formation will increase the difficulty and risk of reoperation. Previous studies demonstrated that symptomatic pseudarthrosis is the main cause of reoperation at the treated level, while symptomatic ASD is responsible for reoperation at adjacent levels [38]. Hence, we inferred that the preservation of segmental motion can provide a physical FSU and avoid the generation of pseudarthrosis, which can reduce the reoperation rate at the index level. Meanwhile, a normal segmental mobility after surgery can decrease the excessive motion of adjacent levels and avert the occurrence of ASD, which leads to a low rate of reoperation at adjacent segments.

\section{Limitation}

We considered that the results of the present metaanalysis may be affected by the following reasons: First, the number of included studies was small, which may lead to insufficient evidence. Meanwhile, some included 
studies were sponsored by companies, which may have introduced some confounding factors. Second, some results have moderate heterogeneity, which may introduce bias. Though we conducted publication bias and sensitivity assessment to consolidate the stability, these results still need to be interpreted with caution. Third, the use of cervical prothesis in different studies was not coincident. Given the limited data, subgroup analysis is difficult to perform according to different devices. Fourth, the reasons for reoperation may sometimes depend on the surgeon's preference, which will also bring bias to the results. Fifth, though some variables showed significant differences between two groups, the overall effects did not across the MCID. Hence, the clinical reference for these data should be considered prudently. Based on the above limitations, we believe that the combined results of the present study should be accepted carefully, and more high-quality studies with larger samples and detailed data are needed.

\section{Conclusion}

For the treatment of CDDDs, CDA is superior than ACDF in terms of improving clinical outcomes, preserving the ROM, ASD incidence, and reoperation rate at long-term follow-up. However, more high-quality, largesample, and strong-evidenced studies are needed to verify our results.

\section{Supplementary information}

Supplementary information accompanies this paper at https://doi.org/10. 1186/s12883-020-01717-0.

Additional file 1.

Additional file 2

\section{Acknowledgements}

The present study was supported by The First Affiliated Hospital of Soochow University.

\section{Authors' contributions}

YJ Z and NN L contributed equally to this work. YJ Z and XS Z designed the study and did the literature search, study quality assessment and data extraction. F H, B P, H L and A C performed the statistical analysis and drafted the tables and Figs. YJ Z wrote the first draft of this analysis, $H L Y$, $M M L$ helped to finish the final version. $N N L$ and $M M L$ helped with revision of the manuscript. All authors approved the conclusions of our study.

\section{Funding}

The study supported by "Project of Jiangsu Bureau of traditional Chinese Medicine, YB201964" and "The 16th batch of "Six Talent Peak" project of Jiangsu Province, 2019-WSN-282". The funding body played no role in the design of the study and collection, analysis, and interpretation of data.

\section{Availability of data and materials}

All data generated or analyzed in this work are included in the published version.

Ethics approval and consent to participate Not applicable.
Consent for publication

Not applicable.

\section{Competing interests}

All authors confirmed no competing interest in this work.

\section{Author details}

1'Department of Orthopedics, The First Affiliated Hospital of Soochow University, 899, Pinghai Road, Suzhou 215006, China. ${ }^{2}$ Orthopedic Institute, Soochow University, Suzhou 215006, China. ${ }^{3}$ Department of Orthopedic Surgery, The Second People's Hospital of Lianyungang, Lianyungang 222003, Jiangsu, China. ${ }^{4}$ School of Public Health and Health Systems, University of Waterloo, Waterloo, Ontario N2L 3G1, Canada.

Received: 29 May 2019 Accepted: 2 April 2020

Published online: 20 April 2020

\section{References}

1. Yudoyono F, Cho PG, Park SH, et al. Factors associated with surgical outcomes of cervical ossification of the posterior longitudinal ligament [J]. Medicine. 2018:97(29):e11342.

2. Ren J, Li R, Zhu K, et al. Biomechanical comparison of percutaneous posterior endoscopic cervical discectomy and anterior cervical decompression and fusion on the treatment of cervical spondylotic radiculopathy [J]. J Orthop Surg Res. 2019:14(1):71.

3. Zhang D, Liu B, Zhu J, et al. Comparison of clinical and radiologic outcomes between self-locking stand-alone cage and cage with anterior plate for multilevel anterior cervical discectomy and fusion: a meta-analysis [J]. World Neurosurg. 2019;125:e117-31.

4. Vleggeert-lankamp $\mathrm{CL}$, Janssen $\mathrm{TMH}$, Van Zwet $\mathrm{E}$, et al. the NECK trial: effectiveness of anterior cervical discectomy with or without interbody fusion and arthroplasty in the treatment of cervical disc herniation; a double-blinded randomized controlled trial [J]. The spine journal : official journal of the North American Spine Society. 2018;19(6):965-75.

5. Chang CC, Huang WC, Wu JC, et al. The option of motion preservation in cervical Spondylosis: cervical disc Arthroplasty update [J]. Neurospine. 2018; 15(4):296-305

6. Hill P, Vaishnav A, Kushwaha B, et al. Comparison of inpatient and outpatient preoperative factors and postoperative outcomes in 2-level cervical disc Arthroplasty [J]. Neurospine. 2018;15(4):376-82.

7. Lei T, Liu Y, Wang H, et al. Clinical and radiological analysis of Bryan cervical disc arthroplasty: eight-year follow-up results compared with anterior cervical discectomy and fusion [J]. Int Orthop. 2016;40(6):1197-203.

8. Sasso RC, Anderson PA, Riew KD, et al. Results of cervical arthroplasty compared with anterior discectomy and fusion: four-year clinical outcomes in a prospective, randomized controlled trial [J]. J Bone Joint Surg Am. 2011; 93(18):1684-92.

9. Grasso G. Clinical and radiological features of hybrid surgery in multilevel cervical degenerative disc disease [J]. European spine journal : official publication of the European Spine Society, the European Spinal Deformity Society, and the European Section of the Cervical Spine Research Society, 2015, 24 Suppl 7(842-848).

10. Shangguan L, Ning GZ, Tang $Y$, et al. Discover cervical disc arthroplasty versus anterior cervical discectomy and fusion in symptomatic cervical disc diseases: a meta-analysis [J]. PLoS One. 2017;12(3):e0174822.

11. Zou S, Gao J, Xu B, et al. Anterior cervical discectomy and fusion (ACDF) versus cervical disc arthroplasty (CDA) for two contiguous levels cervical disc degenerative disease: a meta-analysis of randomized controlled trials [J]. European spine journal : official publication of the European Spine Society, the European Spinal Deformity Society, and the European Section of the Cervical Spine Research Society. 2017;26(4):985-97.

12. Page MJ, Moher D. Evaluations of the uptake and impact of the Preferred Reporting Items for Systematic reviews and Meta-Analyses (PRISMA) Statement and extensions: a scoping review [J]. Systematic reviews. 2017; $6(1): 263$.

13. Higgins JP, Altman DG, Gotzsche PC, et al. The Cochrane Collaboration's tool for assessing risk of bias in randomised trials [J]. Bmj. 2011;343:d5928.

14. Angst F, Aeschlimann A, Stucki G. Smallest detectable and minimal clinically important differences of rehabilitation intervention with their implications for required sample sizes using WOMAC and SF-36 quality of life 
measurement instruments in patients with osteoarthritis of the lower extremities [J]. Arthritis Rheum. 2001:45(4):384-91.

15. Katz NP, Paillard FC, Ekman E. Determining the clinical importance of treatment benefits for interventions for painful orthopedic conditions [J]. J Orthop Surg Res. 2015;10:24.

16. Burkus JK, Traynelis VC, Haid RW Jr, et al. Clinical and radiographic analysis of an artificial cervical disc: 7-year follow-up from the prestige prospective randomized controlled clinical trial: clinical article [J]. J Neurosurg Spine. 2014;21(4):516-28.

17. Janssen ME, Zigler JE, Spivak JM, et al. ProDisc-C Total disc replacement versus anterior cervical discectomy and fusion for single-level symptomatic cervical disc disease: seven-year follow-up of the prospective randomized $U$. S. Food and Drug Administration investigational device exemption study [J]. J Bone Joint Surg Am. 2015;97(21):1738-47.

18. Phillips FM, Geisler FH, Gilder KM, et al. Long-term outcomes of the US FDA IDE prospective, randomized controlled clinical trial comparing PCM cervical disc Arthroplasty with anterior cervical discectomy and fusion [J]. Spine. 2015;40(10):674-83.

19. Lanman $\mathrm{TH}$, Burkus JK, Dryer RG, et al. Long-term clinical and radiographic outcomes of the prestige LP artificial cervical disc replacement at 2 levels: results from a prospective randomized controlled clinical trial [J]. J Neurosurg Spine. 2017;27(1):7-19.

20. Radcliff K, Davis RJ, Hisey MS, et al. Long-term Evaluation of Cervical Disc Arthroplasty with the Mobi-C(c) Cervical Disc: A Randomized, Prospective, Multicenter Clinical Trial with Seven-Year Follow-up [J]. International journal of spine surgery. 2017;11:31.

21. Ghobrial GM, Lavelle WF, Florman JE, et al. Symptomatic adjacent level disease requiring surgery: analysis of 10-year results from a prospective, randomized, clinical trial comparing cervical disc Arthroplasty to anterior cervical fusion [J]. Neurosurgery. 2019;84(2):347-54.

22. Hisey MS, Zigler JE, Jackson R, et al. Prospective, Randomized Comparison of One-level Mobi-C Cervical Total Disc Replacement vs. Anterior Cervical Discectomy and Fusion: Results at 5-year Follow-up [J]. International journal of spine surgery. 2016;10:10.

23. Loumeau TP, Darden BV, Kesman TJ, et al. A RCT comparing 7-year clinical outcomes of one level symptomatic cervical disc disease (SCDD) following ProDisc-C total disc arthroplasty (TDA) versus anterior cervical discectomy and fusion (ACDF) [J]. European spine journal : official publication of the European Spine Society, the European Spinal Deformity Society, and the European Section of the Cervical Spine Research Society. 2016;25(7):2263-70.

24. Miller J, Sasso R, Anderson P, et al. Adjacent level degeneration: Bryan Total disc Arthroplasty versus anterior cervical discectomy and fusion [J]. Clinical spine surgery. 2018;31(2):E98-e101.

25. Coric D, Kim PK, Clemente JD, et al. Prospective randomized study of cervical arthroplasty and anterior cervical discectomy and fusion with longterm follow-up: results in 74 patients from a single site [J]. J Neurosurg Spine. 2013;18(1):36-42.

26. Gornet MF, Burkus JK, Shaffrey ME, et al. Cervical Disc Arthroplasty with Prestige LP Disc Versus Anterior Cervical Discectomy and Fusion: Seven-Year Outcomes [J]. International journal of spine surgery. 2016;10:24.

27. Jackson RJ, Davis RJ, Hoffman GA, et al. Subsequent surgery rates after cervical total disc replacement using a Mobi-C cervical disc prosthesis versus anterior cervical discectomy and fusion: a prospective randomized clinical trial with 5-year follow-up [J]. J Neurosurg Spine. 2016;24(5):734-45.

28. Sasso WR, Smucker JD, Sasso MP, et al. Long-term clinical outcomes of cervical disc Arthroplasty: a prospective, randomized, controlled trial [J]. Spine. 2017;42(4):209-16.

29. Burkhardt BW, Brielmaier M, Schwerdtfeger $K$, et al. Smith-Robinson procedure with and without Caspar plating as a treatment for cervical spondylotic myelopathy: a 26-year follow-up of 23 patients [J]. European spine journal : official publication of the European Spine Society, the European Spinal Deformity Society, and the European Section of the Cervical Spine Research Society. 2017;26(4):1246-53.

30. Song Q, He D, Han X, et al. Clinical and radiological outcomes of cervical disc arthroplasty: ten year follow-up study [J]. Int Orthop. 2018; 42(10):2389-96.

31. Luo J, Wang H, Peng J, et al. Rate of Adjacent Segment Degeneration of Cervical Disc Arthroplasty Versus Fusion Meta-Analysis of Randomized Controlled Trials [J]. World Neurosurg. 2018;113:225-31.
32. Dong $L, X u Z$, Chen $X$, et al. The change of adjacent segment after cervical disc arthroplasty compared with anterior cervical discectomy and fusion: a meta-analysis of randomized controlled trials [J]. The spine journal : official journal of the North American Spine Society. 2017;17(10):1549-58.

33. Hu Y, Lv G, Ren $S$, et al. Mid- to long-term outcomes of cervical disc Arthroplasty versus anterior cervical discectomy and fusion for treatment of symptomatic cervical disc disease: a systematic review and meta-analysis of eight prospective randomized controlled trials [J]. PLoS One. 2016;11(2): e0149312.

34. Rao MJ, Nie SP, Xiao BW, et al. Cervical disc arthroplasty versus anterior cervical discectomy and fusion for treatment of symptomatic cervical disc disease: a meta-analysis of randomized controlled trials [J]. Arch Orthop Trauma Surg. 2015;135(1):19-28.

35. Zeng J, Liu H, Wang B, et al. Clinical and radiographic comparison of cervical disc arthroplasty with Prestige-LP Disc and anterior cervical fusion: A minimum 6-year follow-up study [J]. Clin Neurol Neurosurg. 2018;164:97-102.

36. Tian W, Yan K, Han X, et al. Comparison of the clinical and radiographic results between cervical artificial disk replacement and anterior cervical fusion: a 6-year prospective nonrandomized comparative study [J]. Clinical spine surgery. 2017;30(5):E578-e86.

37. Zhao H, Duan LJ, Gao YS, et al. What is the superior surgical strategy for bilevel cervical spondylosis-anterior cervical disc replacement or anterior cervical decompression and fusion?: a meta-analysis from 11 studies [J]. Medicine. 2018;97(13):e0005.

38. Delamarter RB, Zigler J. Five-year reoperation rates, cervical total disc replacement versus fusion, results of a prospective randomized clinical trial [J]. Spine. 2013;38(9):711-7.

\section{Publisher's Note}

Springer Nature remains neutral with regard to jurisdictional claims in published maps and institutional affiliations.

\section{Ready to submit your research? Choose BMC and benefit from:}

- fast, convenient online submission

- thorough peer review by experienced researchers in your field

- rapid publication on acceptance

- support for research data, including large and complex data types

- gold Open Access which fosters wider collaboration and increased citations

- maximum visibility for your research: over $100 \mathrm{M}$ website views per year

At BMC, research is always in progress.

Learn more biomedcentral.com/submissions 